Supporting Information

\title{
Anchoring Carbon-Coated CoSe Nanoparticles on Hollow Carbon Nanocapsules for Efficient Potassium Storage
}

Zhuangzhuang Zhang, Beining Zhang, Jingyi Xu, Min Zhang, Liping Duan, Jian Shen, * and Xiaosi Zhou*

Jiangsu Key Laboratory of New Power Batteries, Jiangsu Collaborative Innovation Center of Biomedical Functional Materials, School of Chemistry and Materials Science, Nanjing Normal University, Nanjing 210023, China

*Corresponding authors

E-mail: zhouxiaosi@njnu.edu.cn

E-mail: jshen@njnu.edu.cn 

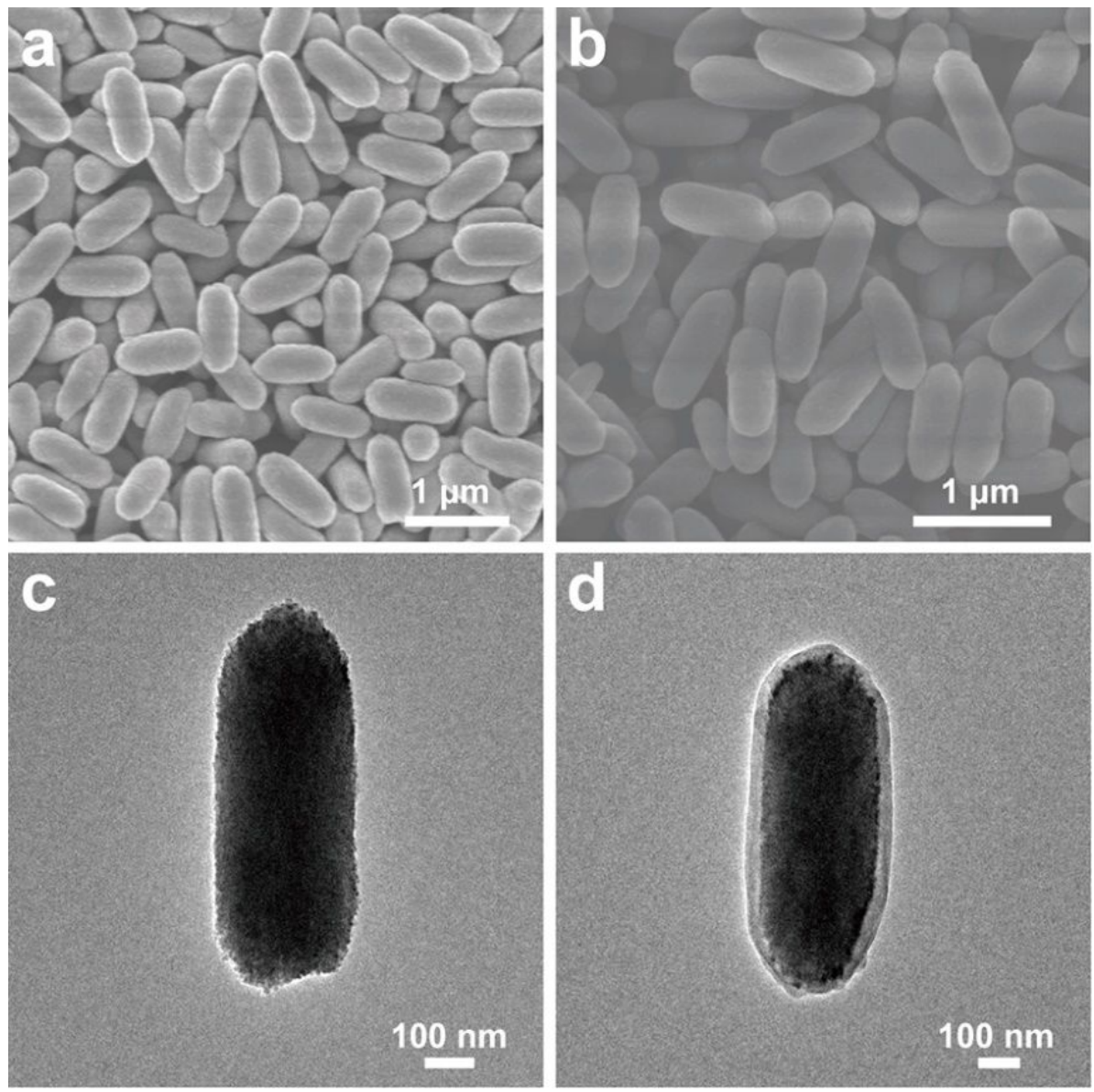

Figure S1. (a) SEM image and (c) TEM image of $\mathrm{Fe}_{2} \mathrm{O}_{3}$ nanocapsules. (b) SEM image and (d) TEM image of $\mathrm{Fe}_{2} \mathrm{O}_{3} @ \mathrm{C}$ nanocapsules. 

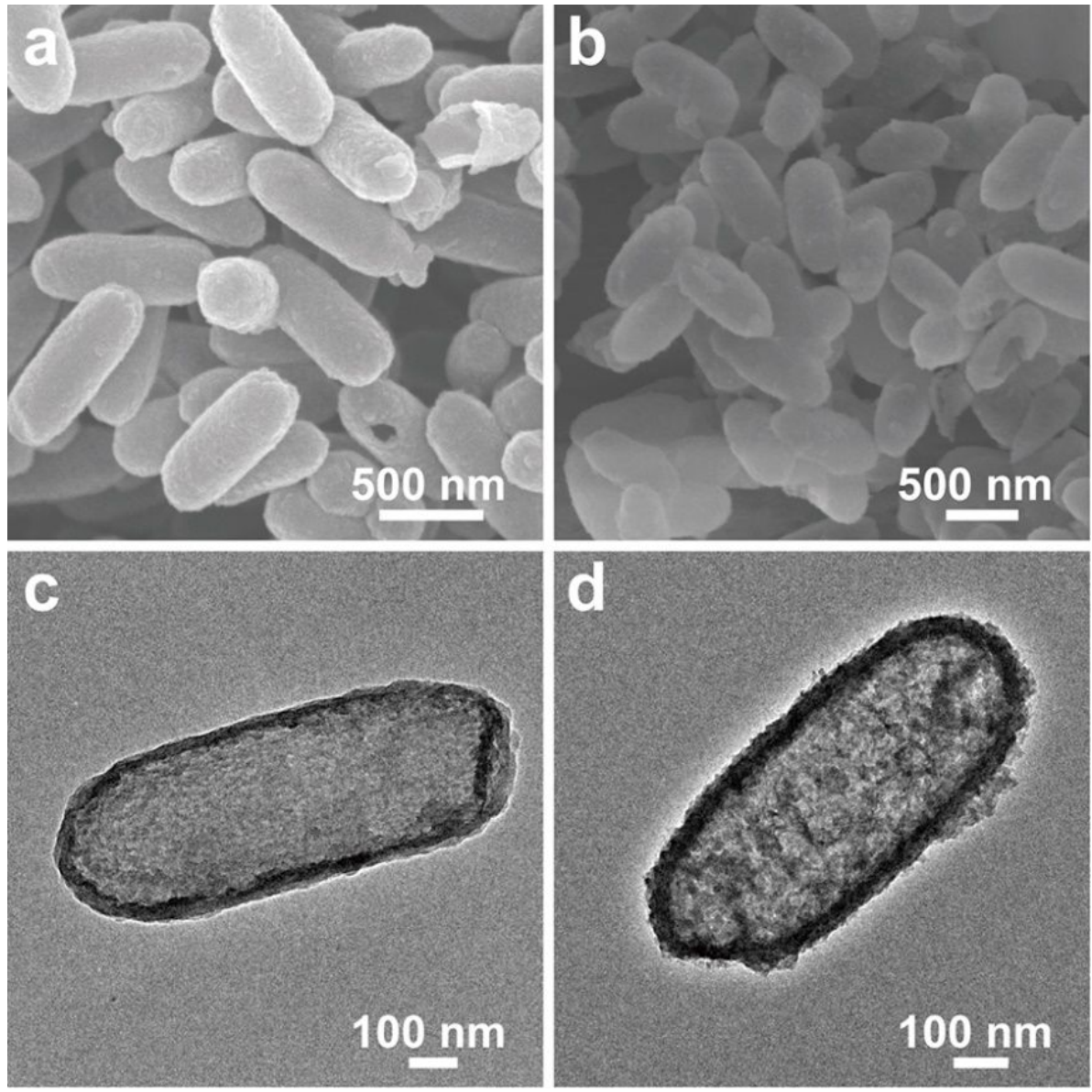

Figure S2. (a) SEM image and (c) TEM image of hollow carbon nanocapsules (HCPs). (b) SEM image and (d) TEM image of conformal coating of a Co-glycolate layer on HCPs (denoted as CoG/HCPs). 


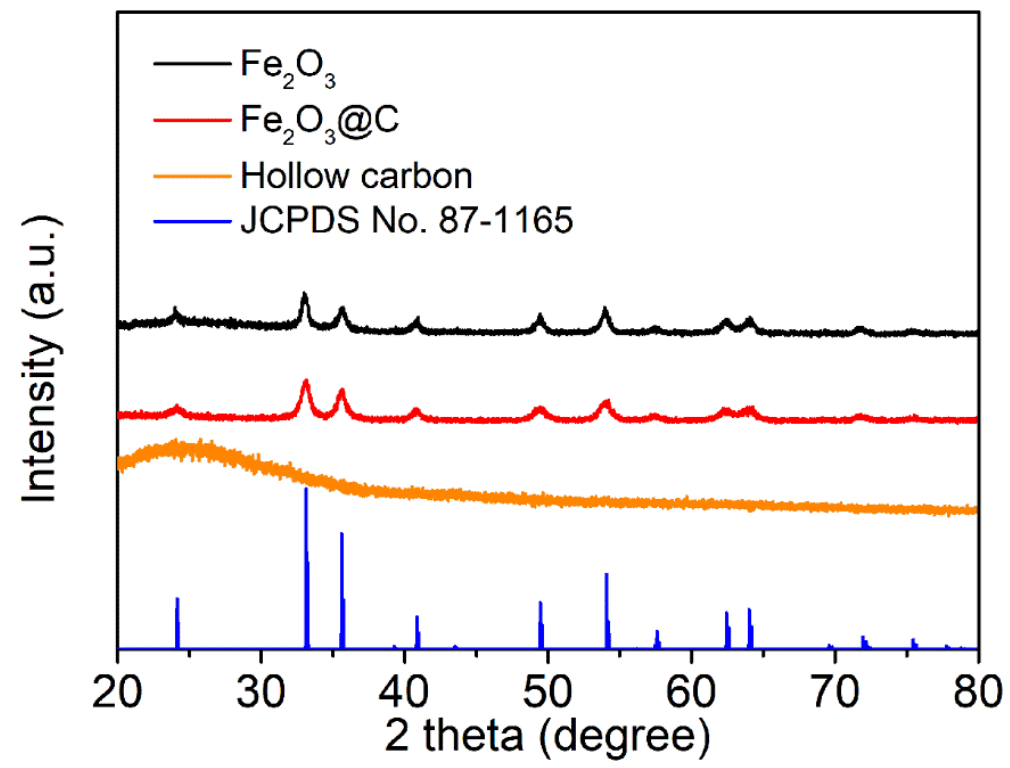

Figure S3. XRD patterns of $\mathrm{Fe}_{2} \mathrm{O}_{3}$ nanocapsules, $\mathrm{Fe}_{2} \mathrm{O}_{3} @ \mathrm{C}$ nanocapsules, and HCPs. 

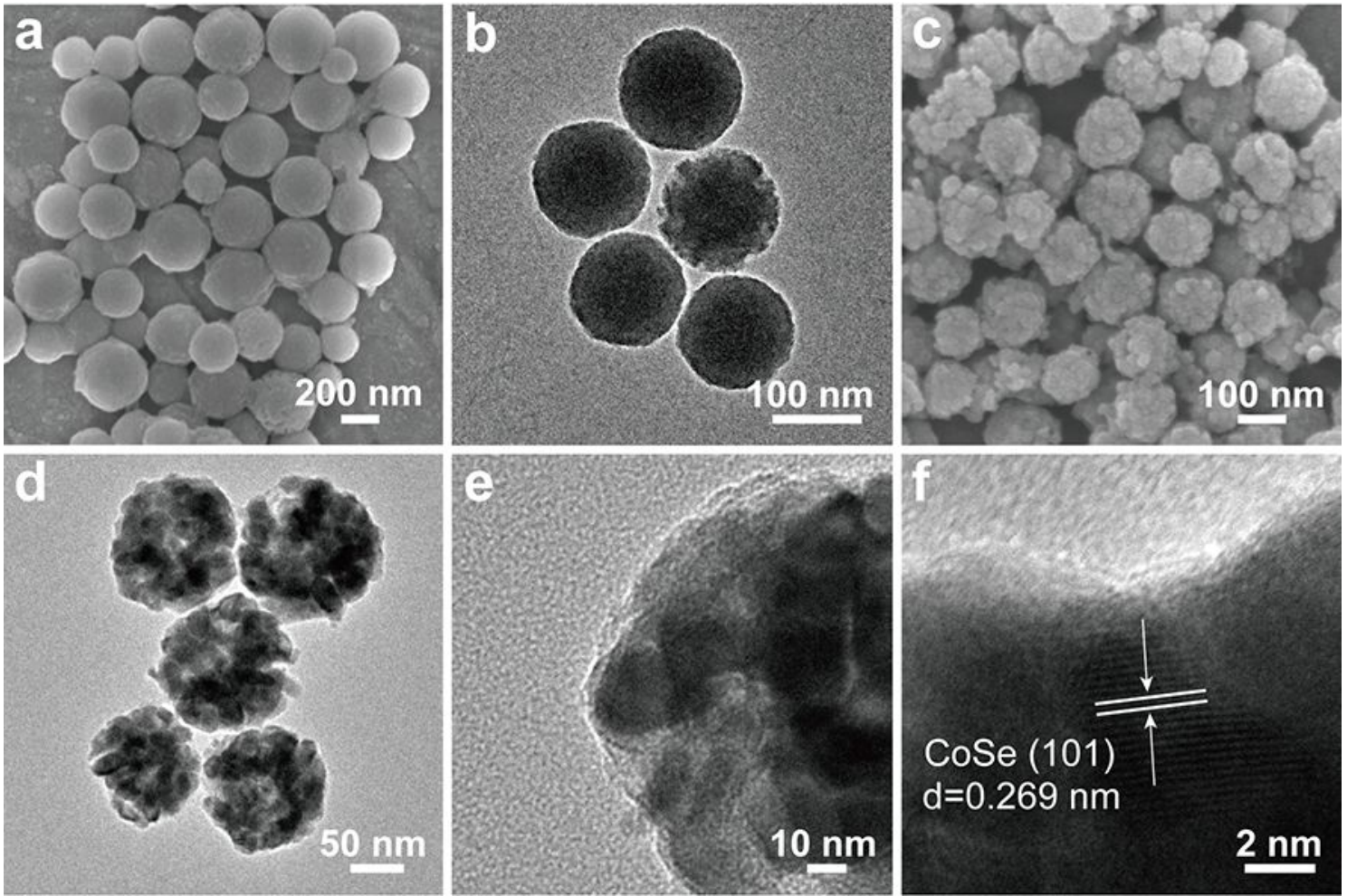

Figure S4. (a) SEM image and (b) TEM image of Co-glycolate (Co-G) nanoparticles. (c) SEM image and (d, e) TEM images, and (f) HRTEM image of CoSe@carbon nanoparticles (CoSe@C NPs). 


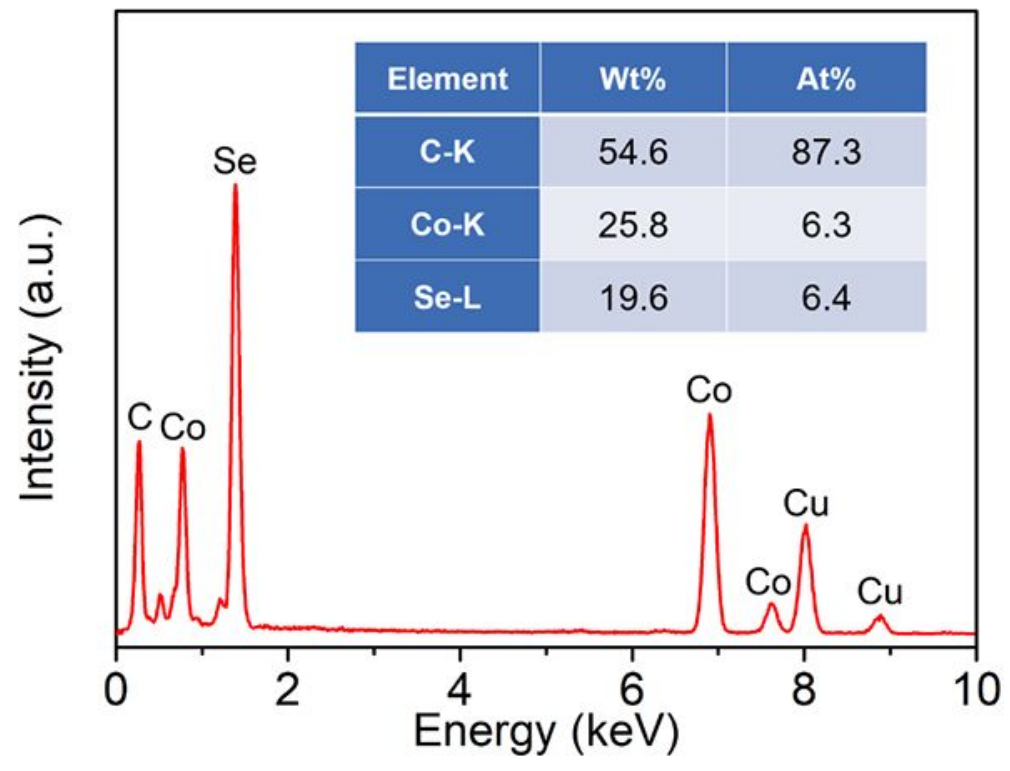

Figure S5. Energy-dispersive X-ray spectroscopy (EDX) spectrum of uniformly anchored CoSe@C nanoparticles on HCPs (denoted as CoSe@C/HCPs). 

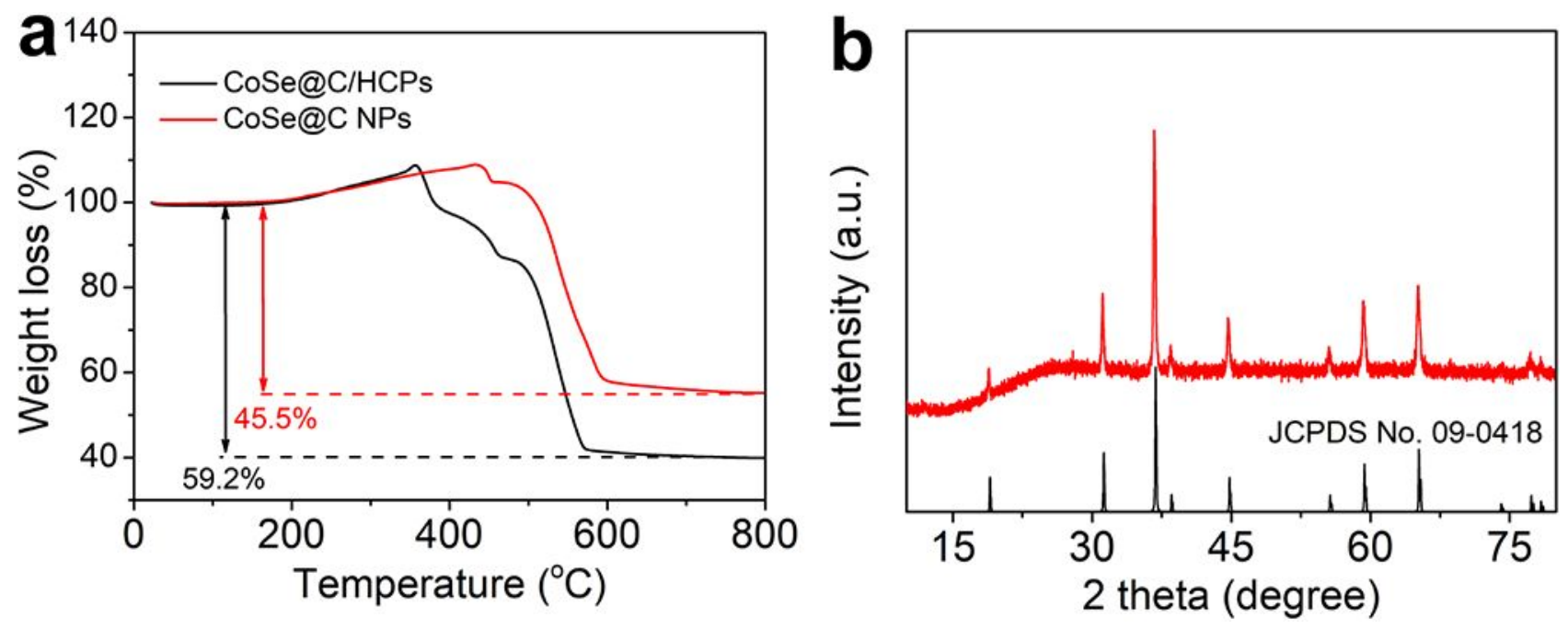

Figure S6. (a) Thermogravimetric analysis (TGA) of CoSe@C/HCPs and CoSe@C NPs. (b) XRD pattern of the remains after TGA test, indicating the formation of $\mathrm{Co}_{3} \mathrm{O}_{4}$.

The calculation of carbon content in the samples: The weight loss below $200{ }^{\circ} \mathrm{C}$ was attributed to the evaporation of absorbed water, while the slight increase can be assigned to the oxidation of cobalt and selenium species between 200 and $400{ }^{\circ} \mathrm{C}$. The weight loss after $400{ }^{\circ} \mathrm{C}$ can be ascribed to the conversion of $\mathrm{CoSe}$ to $\mathrm{Co}_{3} \mathrm{O}_{4}$ and combustion of carbon. For CoSe@C/HCPs and CoSe@C NPs, the weight loss is 59.2\% and 45.5\%, respectively. Taking CoSe@C/HCPs as an example, the content of carbon in CoSe@C/HCPs is calculated based on the following conversion: ${ }^{1}$

$$
\begin{gathered}
\mathrm{CoSe} @ \mathrm{C} / \mathrm{HCPs} \rightarrow \mathrm{Co}_{3} \mathrm{O}_{4}+\text { gas } \quad \text { Atomic weight: } \mathrm{Co}(59), \mathrm{Se}(79), \mathrm{O}(16) \\
x+\frac{[(59+79)-(59 * 3+16 * 4) / 3](1-x)}{59+79}=59.2 \%
\end{gathered}
$$

The total weight percentage of CoSe@C/HCPs is regarded as $100 \%$, while the carbon weight percentage is $x$. According to the above equation, the carbon content of CoSe@C/HCPs is calculated to be $29.9 \%$. In the same way, the carbon content of CoSe@C NPs is calculated to be $6.3 \%$. 


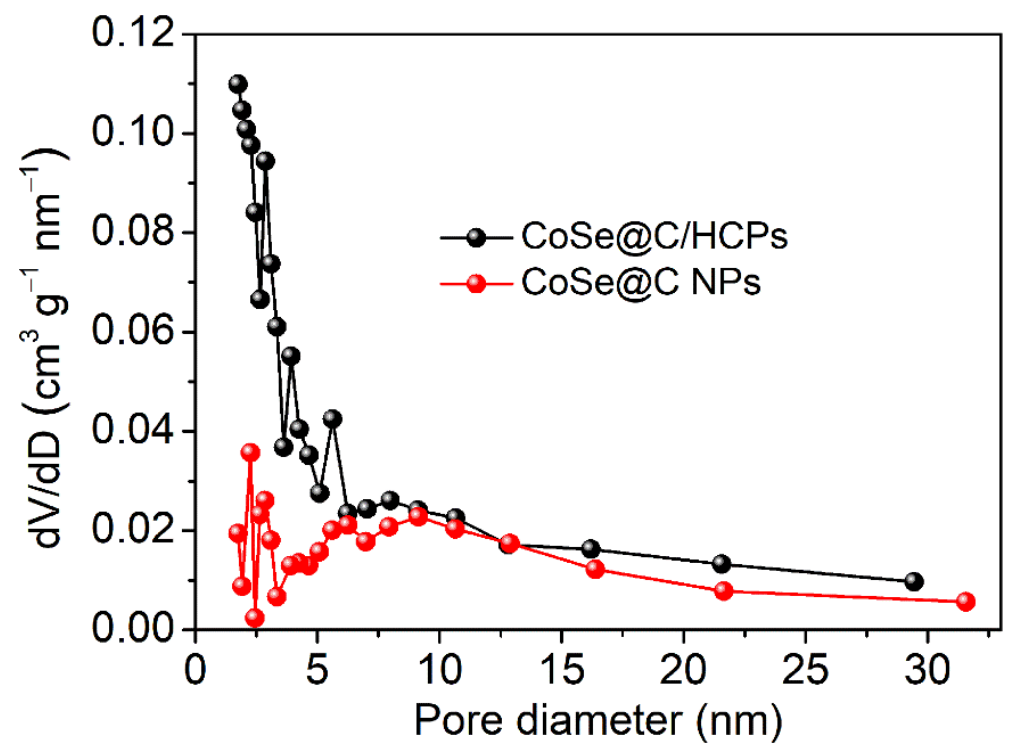

Figure S7. Pore size distribution of CoSe@C/HCPs and CoSe@C NPs. 

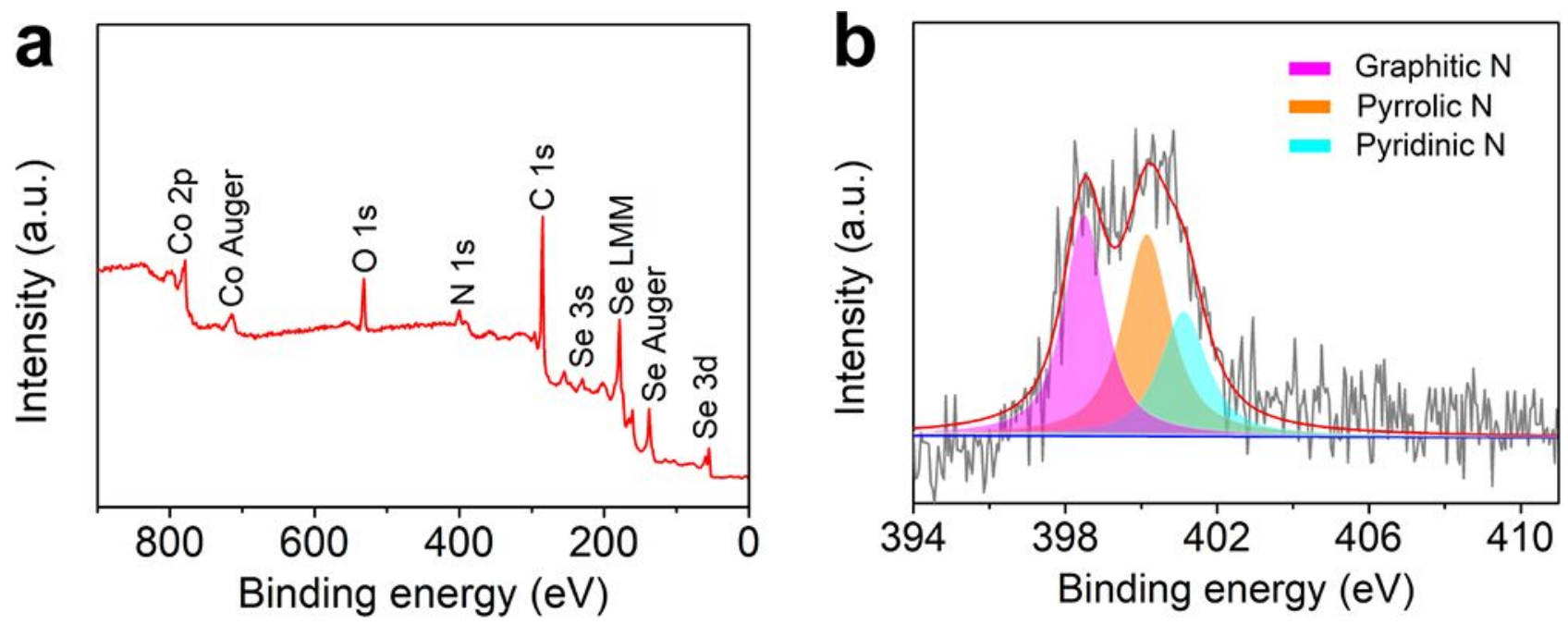

Figure S8. XPS spectra of CoSe@C/HCPs: (a) survey spectrum and (b) high-resolution N 1s XPS spectrum. 

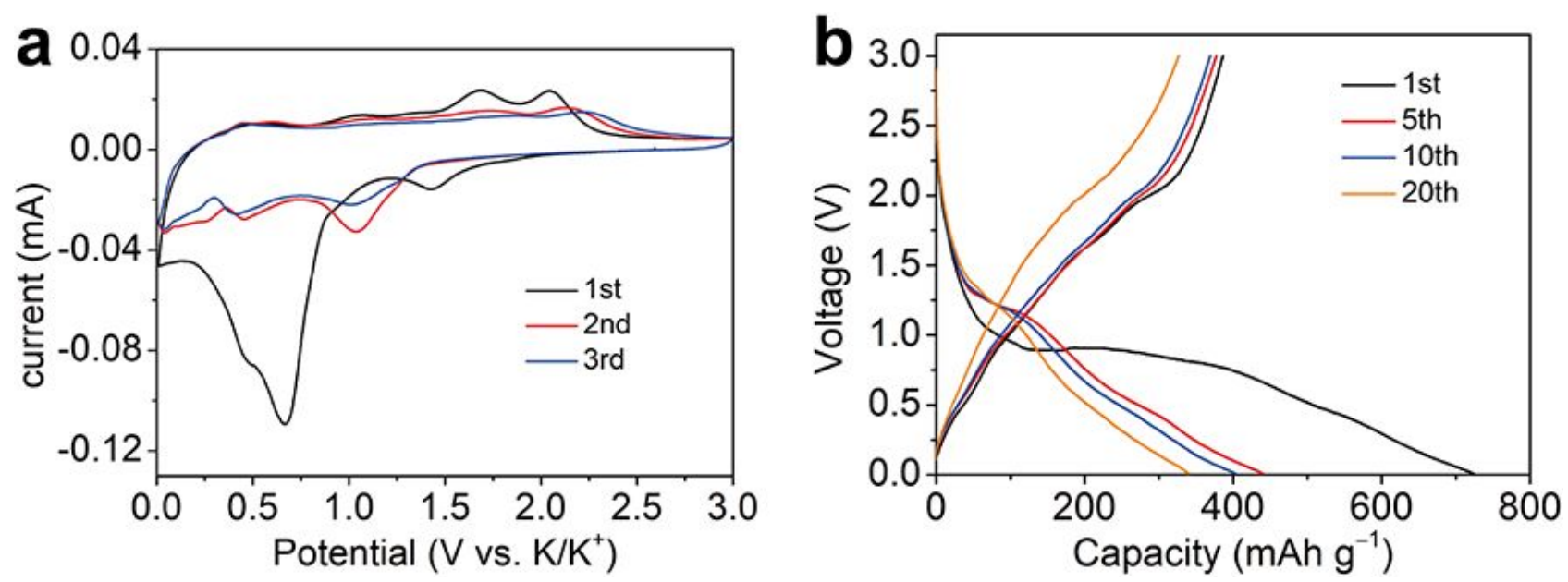

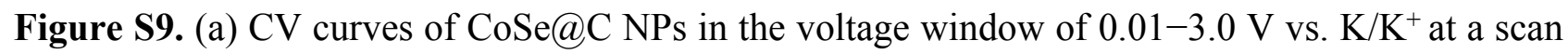
rate of $0.1 \mathrm{mV} \mathrm{s}^{-1}$. (b) Typical discharge/charge profiles of CoSe@C NPs at a current density of 0.1 $\mathrm{A} \mathrm{g}^{-1}$. 


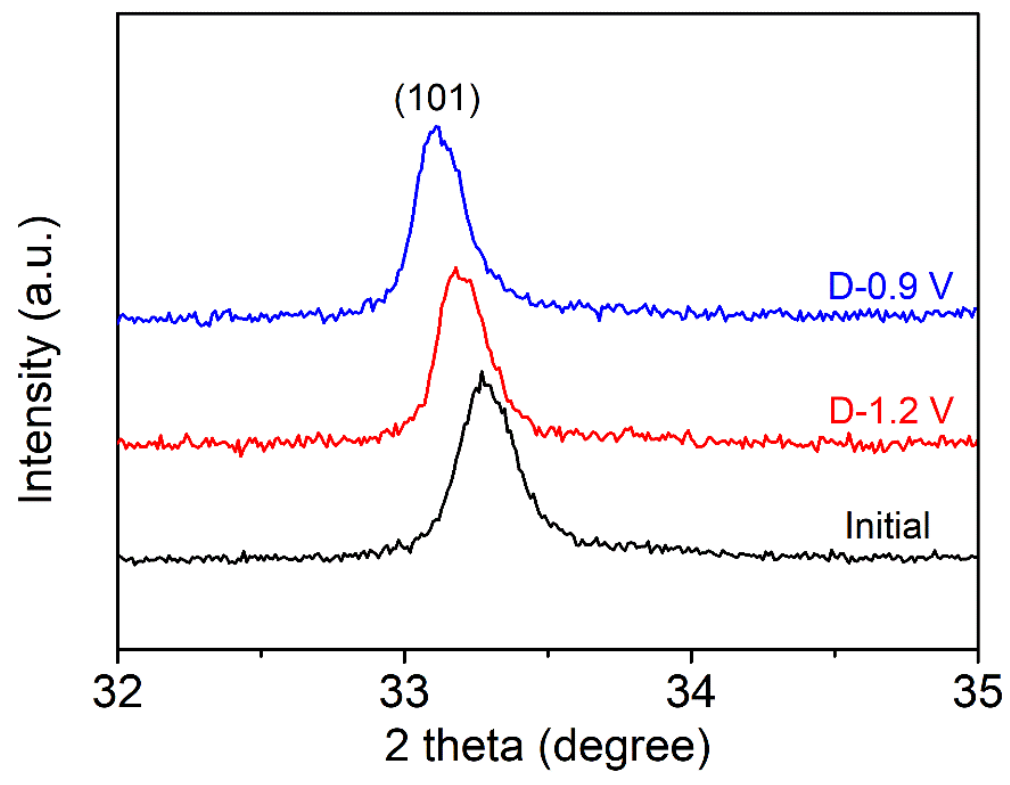

Figure S10. Enlarged view of the (101) diffraction peak during the ex-situ XRD measurements. 

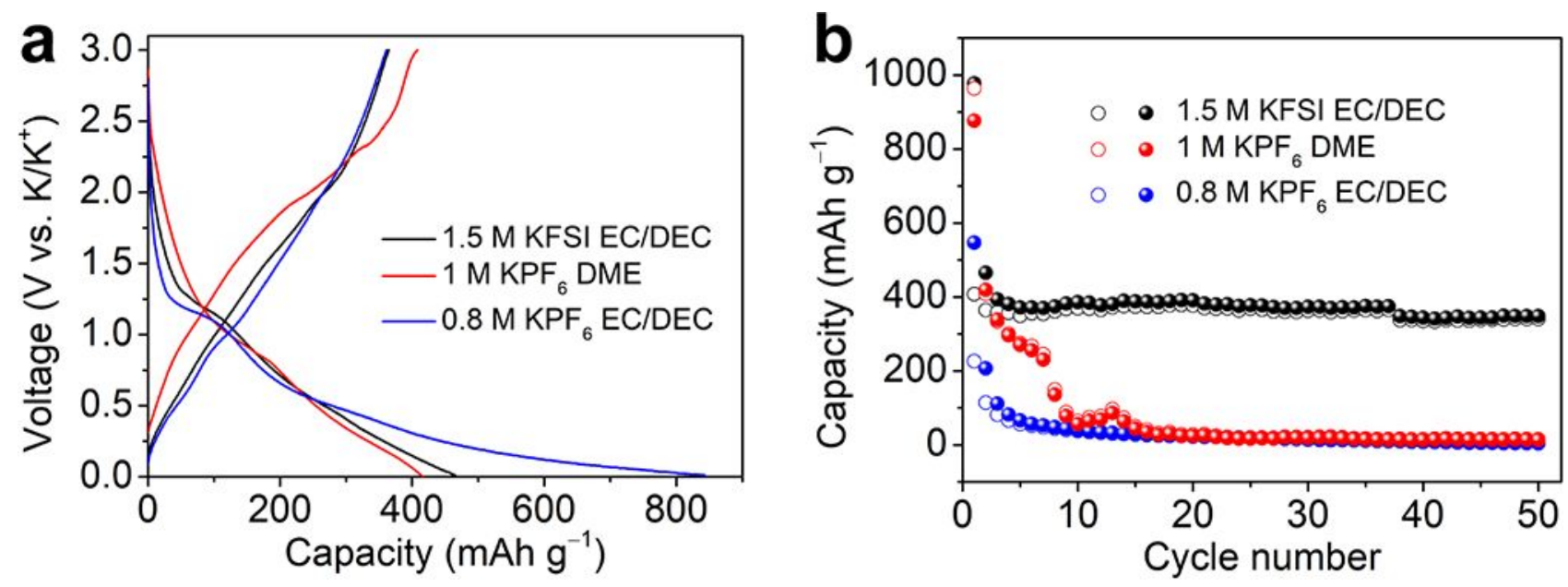

Figure S11. (a) Typical discharge/charge profiles and (b) cycling performance of CoSe@C/HCPs in different electrolytes at $100 \mathrm{~mA} \mathrm{~g}^{-1}$. 
Table S1. Comparison of potassium storage properties of the reported the Se-based anode materials.

\begin{tabular}{|c|c|c|c|c|}
\hline Materials & $\begin{array}{l}\text { Reversible capacity } \\
\qquad\left(\mathrm{mAh} \mathrm{g}^{-1}\right)\end{array}$ & Cycling stability & $\begin{array}{l}\text { Rate capability } \\
\qquad\left(\mathrm{mAh} \mathrm{g}^{-1}\right)\end{array}$ & Reference \\
\hline CoSe@C/HCPs & $461\left(100 \mathrm{~mA} \mathrm{~g} \mathrm{~g}^{-1}\right)$ & $58 \%$ (300 cycles) & $278\left(3 \mathrm{~A} \mathrm{~g}^{-1}\right)$ & This work \\
\hline CoSe@NCNT & $435\left(100 \mathrm{~mA} \mathrm{~g}^{-1}\right)$ & $99 \%$ (500 cycles $)$ & $278\left(3 \mathrm{~A} \mathrm{~g}^{-1}\right)$ & 1 \\
\hline $\mathrm{Co}_{0.85} \mathrm{Se} @ \mathrm{CNFs}$ & $308\left(200 \mathrm{~mA} \mathrm{~g}^{-1}\right)$ & $97 \%$ (400 cycles) & $166\left(5 \mathrm{~A} \mathrm{~g}^{-1}\right)$ & 2 \\
\hline $\mathrm{CoSe}_{2} @ \mathrm{NC} / \mathrm{HMCS}$ & $472\left(100 \mathrm{~mA} \mathrm{~g}^{-1}\right)$ & $93 \%$ (120 cycles $)$ & $263\left(2 \mathrm{~A} \mathrm{~g}^{-1}\right)$ & 3 \\
\hline $\mathrm{Co}_{0.85} \mathrm{Se} / \mathrm{G}$ & $795\left(50 \mathrm{~mA} \mathrm{~g}^{-1}\right)$ & $41 \%$ (200 cycles $)$ & $260\left(1 \mathrm{~A} \mathrm{~g}^{-1}\right)$ & 4 \\
\hline CSNS/NCF & $340\left(50 \mathrm{~mA} \mathrm{~g}^{-1}\right)$ & $98 \%$ (200 cycles $)$ & $226\left(2 \mathrm{~A} \mathrm{~g}^{-1}\right)$ & 5 \\
\hline CoSe@NrGo & $408\left(50 \mathrm{~mA} \mathrm{~g}^{-1}\right)$ & $41 \%$ (100 cycles $)$ & $143\left(2 \mathrm{~A} \mathrm{~g} \mathrm{~g}^{-1}\right)$ & 6 \\
\hline $\mathrm{Co}_{0.85} \mathrm{Se}-\mathrm{QDs} / \mathrm{C}$ & $401\left(50 \mathrm{~mA} \mathrm{~g}^{-1}\right)$ & $81 \%(500$ cycles $)$ & $220\left(2 \mathrm{~A} \mathrm{~g}^{-1}\right)$ & 7 \\
\hline
\end{tabular}




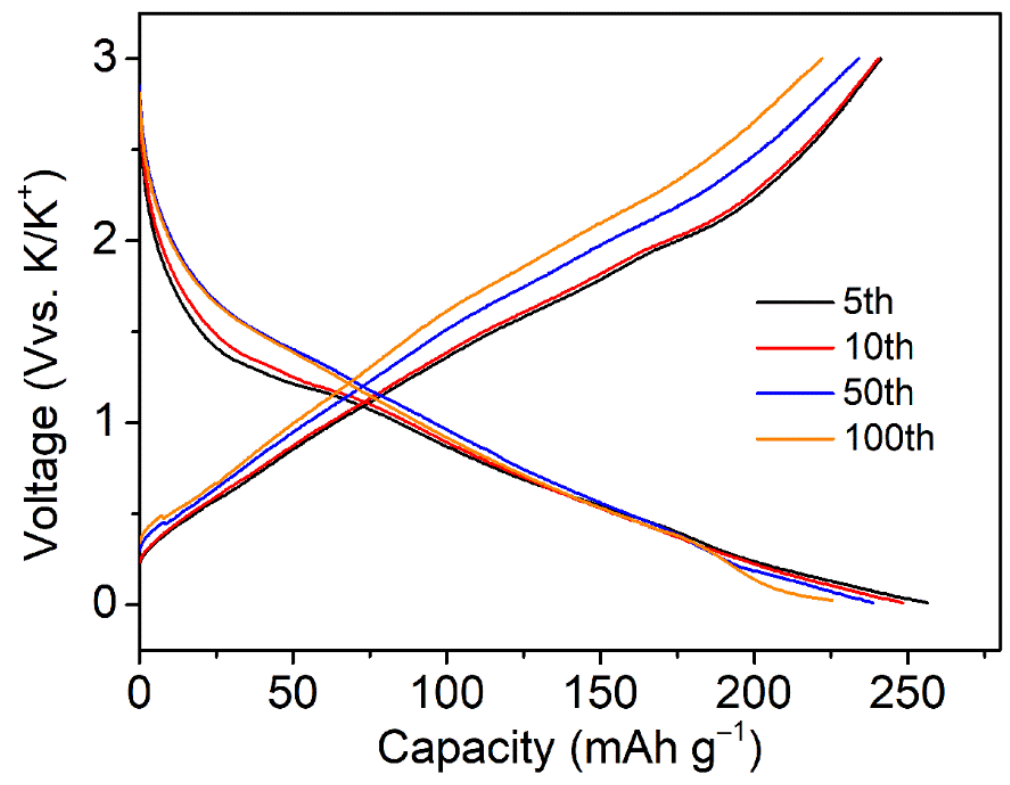

Figure S12. Representative charge-discharge profiles of the CoSe@C/HCPs electrode at $3 \mathrm{~A} \mathrm{~g}^{-1}$. 

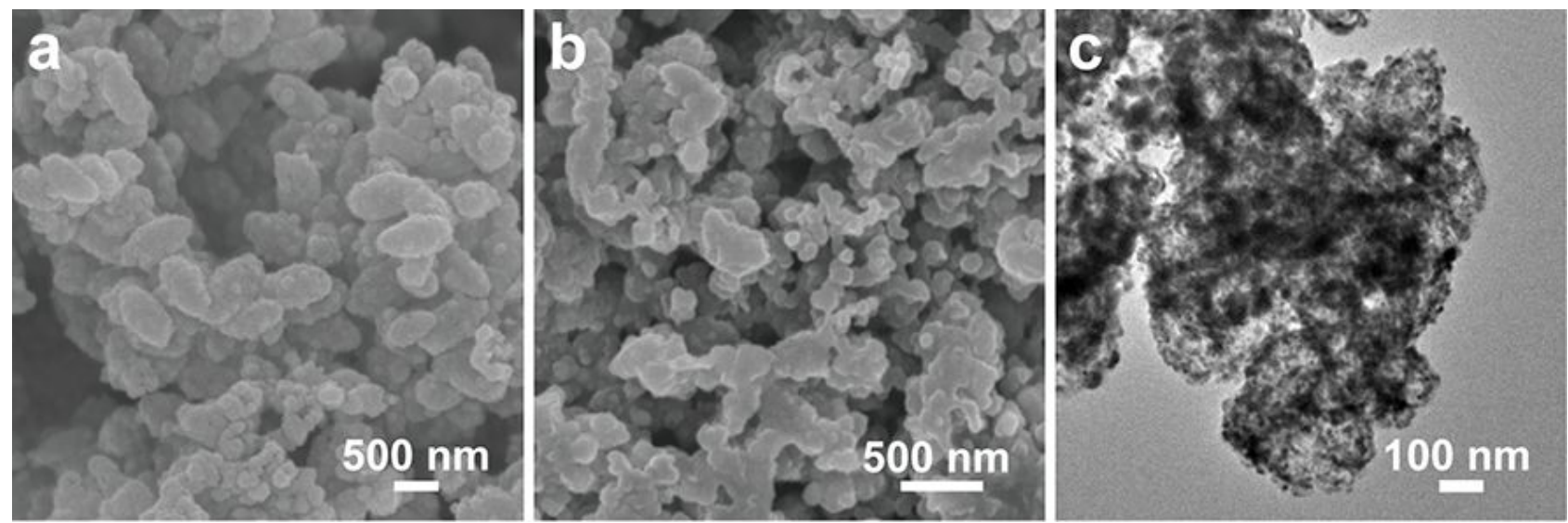

Figure S13. (a) SEM image of CoSe@C/HCPs, (b) SEM image of CoSe@C NPs, and (c) TEM image of CoSe@C/HCPs after 50 cycles at 100 mAh g ${ }^{-1}$. 

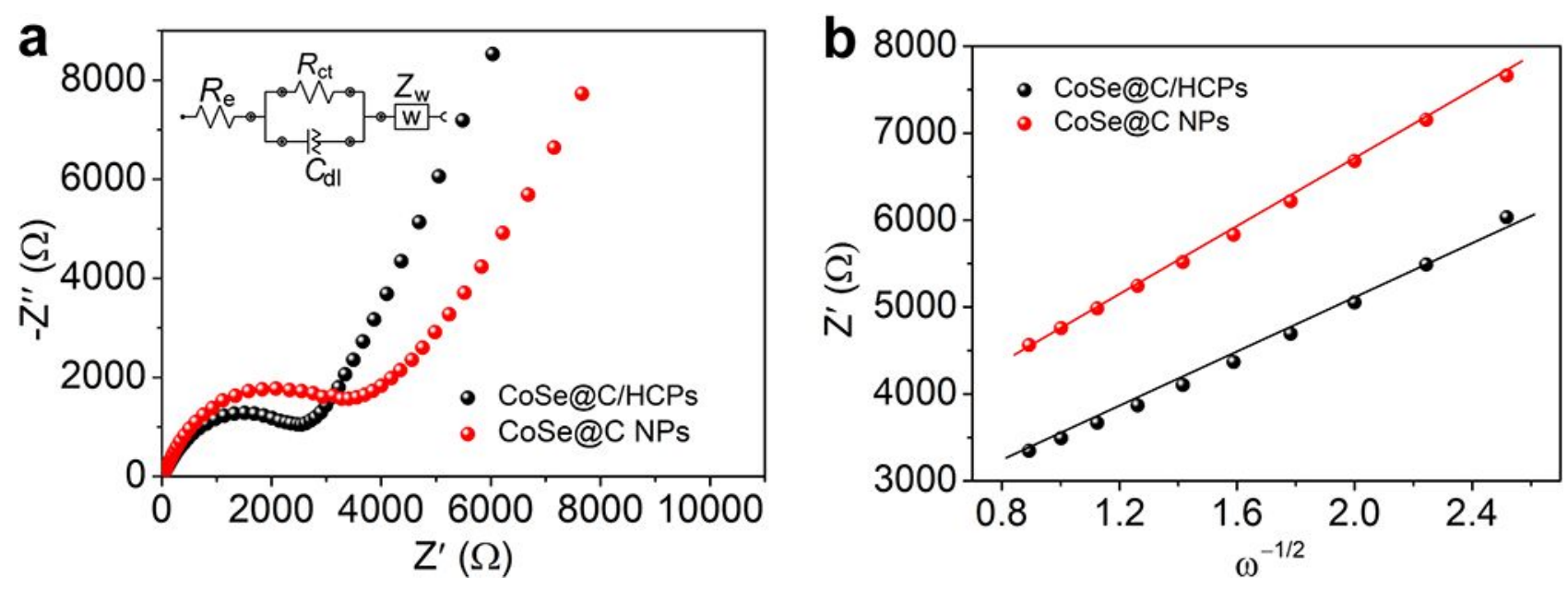

Figure S14. (a) Nyquist plots of the CoSe@C/HCPs and CoSe@C NPs electrodes after 10 cycles. (b) The coefficients of Warburg impedance $(\sigma)$ obtained from the linear fitting of $Z^{\prime}$ versus $\omega^{-1 / 2}$ plots for CoSe@C/HCPs and CoSe@C NPs.

Figure S14a displays the typical electrochemical impedance spectroscopy (EIS) curves of the CoSe@C/HCPs and CoSe@C NPs electrodes. All the Nyquist plots consist of a depressed semicircle in the high-medium frequency region and a linear line in the low frequency region. The former is related to the charge-transfer process $\left(R_{\mathrm{ct}}\right)$ at the electrolyte/electrode interphase, while the latter is associated with the Warburg impedance $\left(Z_{\mathrm{w}}\right)$ corresponding to $\mathrm{K}^{+}$diffusion in $\mathrm{CoSe} @ \mathrm{C} / \mathrm{HCPs}$ and CoSe@C NPs. $R_{\mathrm{e}}$ refers to the electrolyte resistance, and $C_{\mathrm{dl}}$ represents the constant phase elements, usually referring to the double-layer capacitance.

Table S2. the fitted impedance values $\left(R_{\mathrm{e}}\right.$ and $\left.R_{\mathrm{ct}}\right)$, Warburg factors $\left(\sigma_{\mathrm{w}}\right)$, and $\mathrm{K}^{+}$diffusion coefficient of $\left(D_{\mathrm{K}+}\right)$ of the electrodes.
Electrode
$R_{\mathrm{e}}(\Omega)$
$R_{\mathrm{ct}}(\Omega)$
$\sigma_{\mathrm{w}}\left(\Omega \mathrm{s}^{-1 / 2}\right)$
$D_{\mathrm{K}}{ }^{+}\left(\mathrm{cm}^{2} \mathrm{~s}^{-1}\right)$

CoSe@C/HCPs

48

1856

1562

$2.65 \times 10^{-13}$

CoSe@C NPs

69

2756

1964

$1.68 \times 10^{-13}$ 
Table S2 indicates that CoSe@C/HCPs possess smaller $R_{\mathrm{e}}, R_{\mathrm{ct}}$, and $\sigma_{\mathrm{w}}$ than those of CoSe $@ \mathrm{C}$ NPs. These results demonstrate that the large surface area, double-layer carbon protection, and smaller CoSe particle size can synergistically improve the ionic conductivity of the CoSe@C/HCPs electrode.

EIS is also an effective means to calculate $D_{\mathrm{K}+}$ in the samples based on the following Eq. (1): ${ }^{8-9}$

$$
D_{\mathrm{K}^{+}}=\frac{R^{2} T^{2}}{2 A^{2} n^{4} F^{4} C^{2} \sigma_{\mathrm{w}}{ }^{2}}
$$

where $R$ is the gas constant, $T$ means the temperature in Kelvin, $A$ represents the surface area of electrode, $n$ indicates the number of transferred electrons, $F$ is the Faraday constant, $C$ refers to the concentration of $\mathrm{K}^{+}$, and $\sigma_{\mathrm{w}}$ is the Warburg factor. $\sigma_{\mathrm{w}}$ correlates to $Z_{\mathrm{re}}\left(\right.$ i.e., $\left.Z^{\prime}\right)$ through the following Eq. (2) and its value can be achieved from the slope of $Z_{\mathrm{re}} \sim \omega^{-1 / 2}$ plot as demonstrated in Figure S14b.

$$
Z_{\mathrm{re}}=R_{\mathrm{D}}+R_{\mathrm{L}}+\sigma \omega^{-1 / 2}
$$

As shown in Table S2, the $\sigma_{\mathrm{w}}$ of the CoSe@C/HCPs electrode is smaller (1562), reflecting the larger $D_{\mathrm{K}+}$ value $\left(2.65 \times 10^{-13} \mathrm{~cm}^{2} \mathrm{~s}^{-1}\right)$. This result further demonstrates that the double-layer carbon protection and smaller CoSe particle size can synergistically enhance the $\mathrm{K}^{+}$diffusion kinetics. 

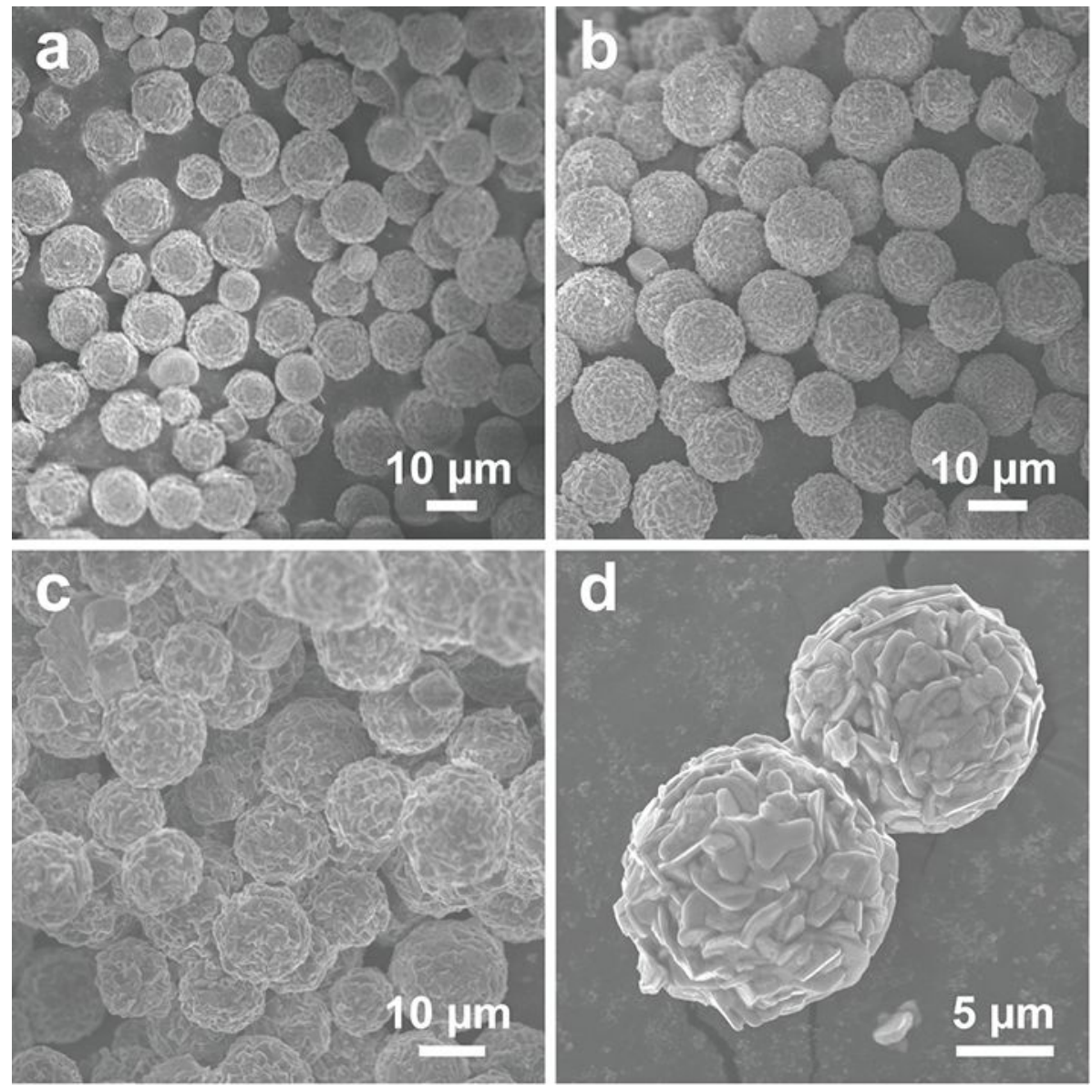

Figure S15. (a) SEM image of $\mathrm{CoCO}_{3}$ microspheres, (b) SEM image of $\mathrm{Co}_{3} \mathrm{O}_{4}$ microspheres, and (c, d) SEM images of $\mathrm{P}_{2}$-type $\mathrm{K}_{0.6} \mathrm{CoO}_{2}$ microspheres. 
Table S3. Chemical composition analysis of the as-prepared $\mathrm{P} 2-\mathrm{K}_{0.6} \mathrm{CoO}_{2}$ microspheres based on inductively coupled plasma-optical emission spectroscopy (ICP-OES) test.

Molar ratio

\begin{tabular}{lcc} 
Composition & \multicolumn{2}{c}{ K } \\
\cline { 2 - 3 } & $\mathrm{Co}$ \\
\hline $\mathrm{P} 2-\mathrm{K}_{0.6} \mathrm{CoO}_{2}$ & 0.592 & 1.0 \\
\hline
\end{tabular}




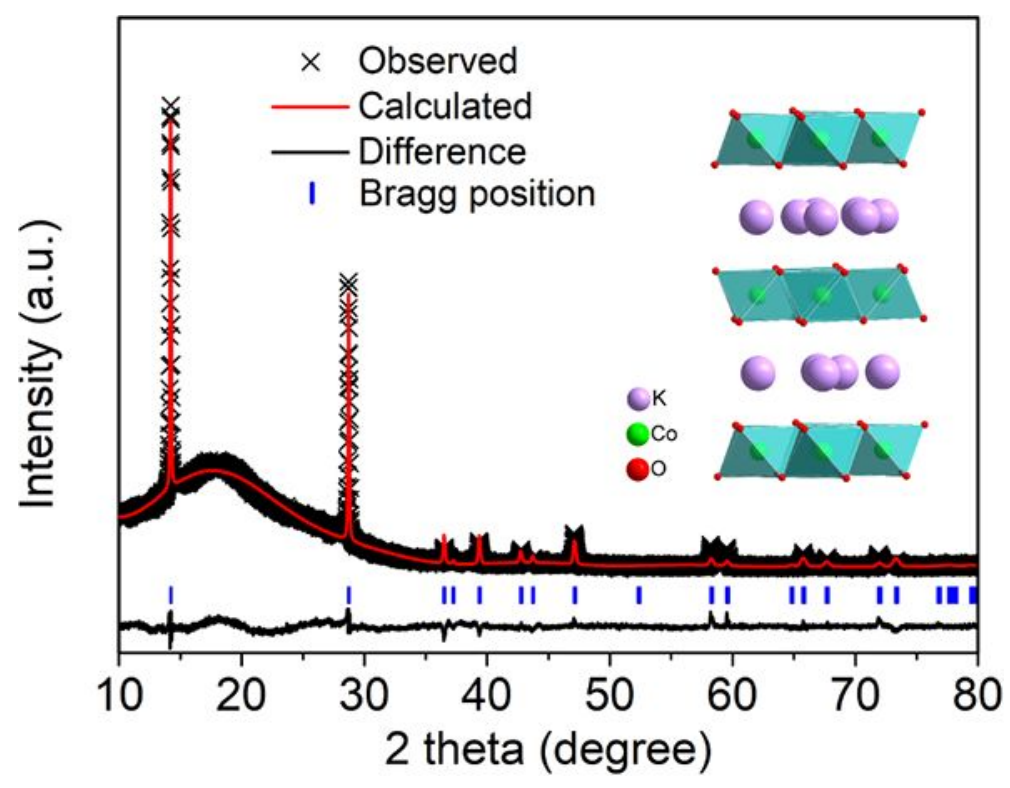

Figure S16. Rietveld refinement of X-ray diffraction data and schematic structure of the $\mathrm{P}_{2}$-type $\mathrm{K}_{0.6} \mathrm{CoO}_{2}$ microspheres. 
Table S4. Crystallographic parameters of $\mathrm{P}_{2}$-type $\mathrm{K}_{0.6} \mathrm{CoO}_{2}$ refined based on the Rietveld method.

\begin{tabular}{ccccc}
\hline Atom & Occupancy & $\mathrm{x}$ & $\mathrm{y}$ & $\mathrm{z}$ \\
$\mathrm{K} 1$ & 0.36 & 0 & 0 & 0.25 \\
$\mathrm{~K} 2$ & 0.54 & 0.67 & 0.33 & 0.25 \\
$\mathrm{C} 0$ & 1 & 0 & 0 & 0.02 \\
$\mathrm{O}$ & 1.22 & 0.33 & 0.67 & \\
& & & \\
& Space group: $P 6_{3} / m m c$ & $\mathrm{a}=\mathrm{b}=2.83717 \AA, \mathrm{c}=12.40103 \AA$
\end{tabular}



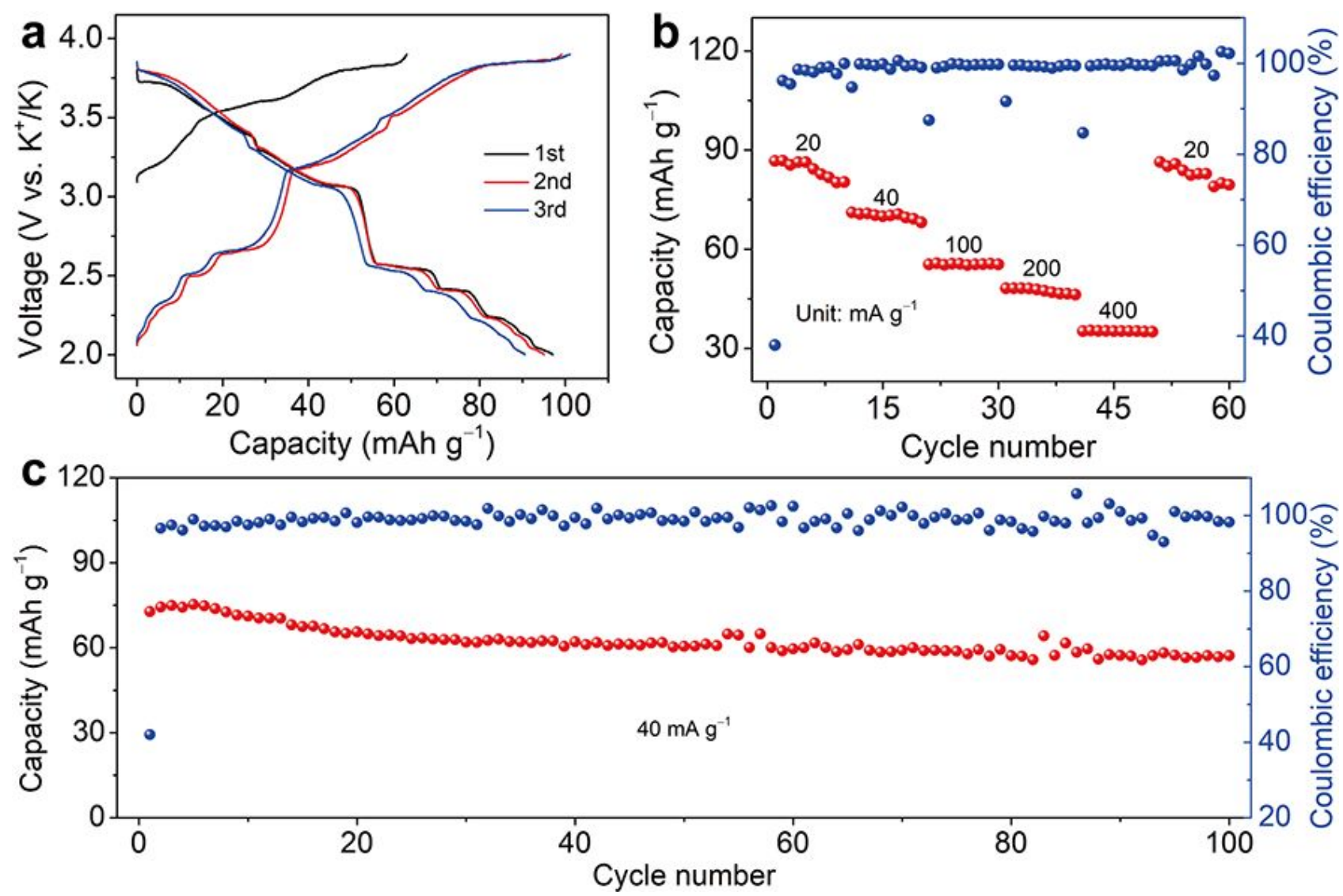

Figure S17. (a) Typical charge/discharge profiles of the $\mathrm{P}_{2}$-type $\mathrm{K}_{0.6} \mathrm{CoO}_{2}$ cathode at a current density of $20 \mathrm{~mA} \mathrm{~g}^{-1}$. (b) Rate capability of $\mathrm{P}_{2}$-type $\mathrm{K}_{0.6} \mathrm{CoO}_{2}$. (c) Cycling performance of $\mathrm{P}_{2}$-type $\mathrm{K}_{0.6} \mathrm{CoO}_{2}$ at $40 \mathrm{~mA} \mathrm{~g}^{-1}$ and the corresponding Coulombic efficiency. 

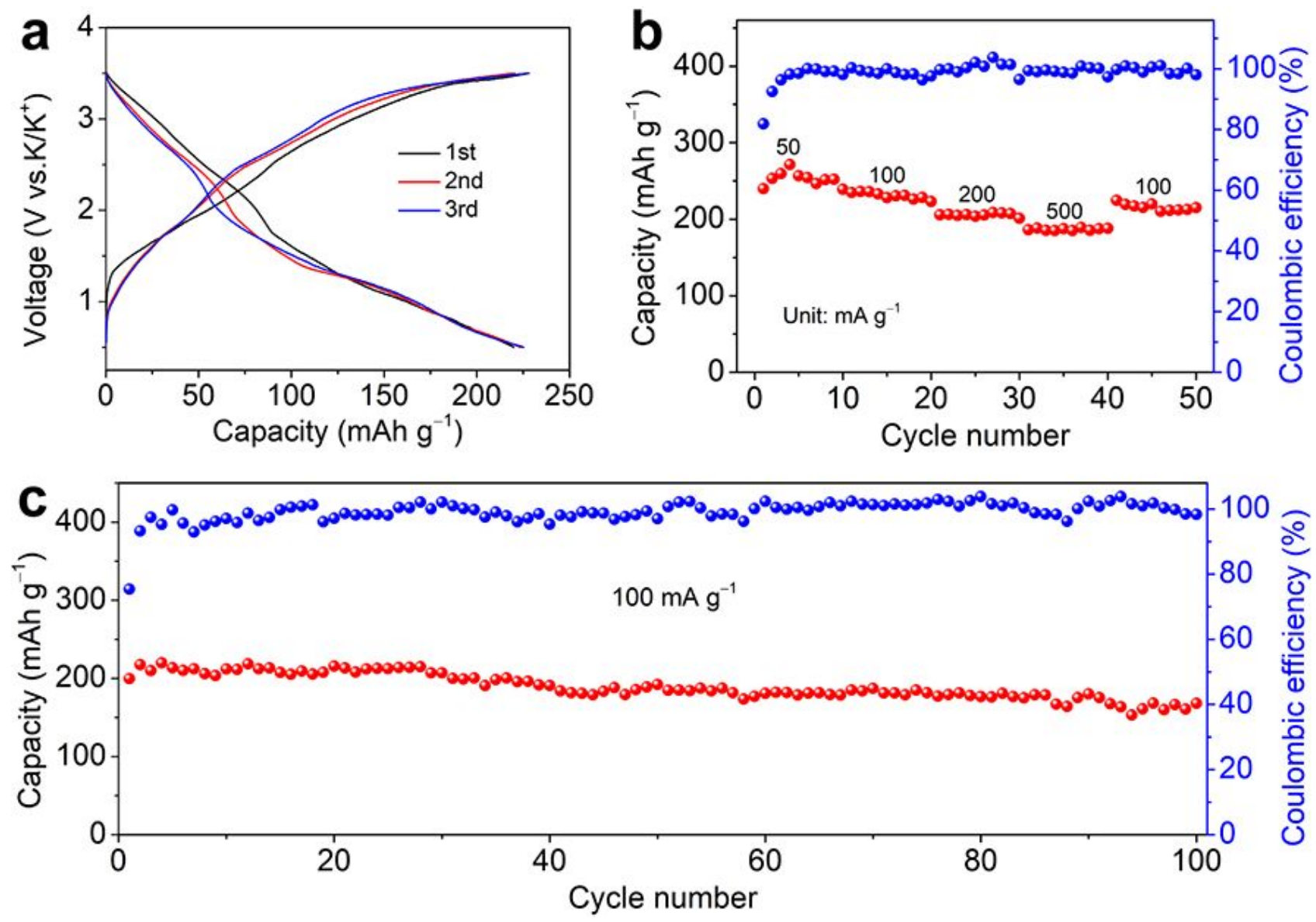

Figure S18. (a) Charge/discharge profiles at $100 \mathrm{~mA} \mathrm{~g}^{-1}$, (b) rate property, and (c) cycling performance at $100 \mathrm{~mA} \mathrm{~g}^{-1}$ of the $\mathrm{P}_{2}$-type $\mathrm{K}_{0.6} \mathrm{CoO}_{2} / / \mathrm{CoSe} @ \mathrm{C} / \mathrm{HCPs}$ potassium-ion full battery.

\section{References}

(1) Liu, Y.; Deng, Q.; Li, Y.; Li, Y.; Zhong, W.; Hu, J.; Ji, X.; Yang, C.; Lin, Z.; Huang, K. CoSe@NDoped Carbon Nanotubes as a Potassium-Ion Battery Anode with High Initial Coulombic Efficiency and Superior Capacity Retention. ACS Nano 2021, 15, 1121-1132.

(2) Atangana Etogo, C.; Huang, H.; Hong, H.; Liu, G.; Zhang, L. Metal-Organic-FrameworksEngaged Formation of $\mathrm{Co}_{0.85} \mathrm{Se} @ \mathrm{C}$ Nanoboxes Embedded in Carbon Nanofibers Film for Enhanced Potassium-ion Storage. Energy Storage Mater. 2020, 24, 167-176.

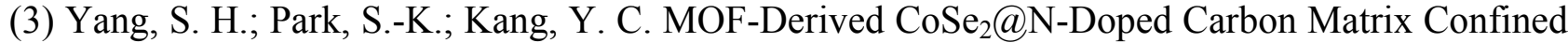
in Hollow Mesoporous Carbon Nanospheres as High-Performance Anodes for Potassium-Ion 
Batteries. Nano-Micro Lett. 2020, 13, 9.

(4) Li, D.; Zhang, J.; Suo, G.; Yu, Q.; Wang, W.; Feng, L.; Hou, X.; Ye, X.; Zhang, L.; Yang, Y. Hollow $\mathrm{Co}_{0.85} \mathrm{Se}$ Cubes Encapsulated in Graphene for Enhanced Potassium Storage. J. Electroanal. Chem. 2020, 864, 114100.

(5) Suo, G.; Zhang, J.; Li, D.; Yu, Q.; Wang, W.; He, M.; Feng, L.; Hou, X.; Yang, Y.; Ye, X.; Zhang, L. N-Doped Carbon/Ultrathin 2D Metallic Cobalt Selenide Core/Sheath Flexible Framework Bridged by Chemical Bonds for High-Performance Potassium Storage. Chem. Eng. J. 2020, 388, 124396.

(6) Liu, Y.; Cui, K.; Ma, Z.; Wang, X. Pseudocapacitance-Induced High-Rate Potassium Storage in CoSe@NrGo Hybrid Nanosheets for Potassium-Ion Batteries. Energy Fuels 2020, 34, 10196-10202. (7) Liu, Z.; Han, K.; Li, P.; Wang, W.; He, D.; Tan, Q.; Wang, L.; Li, Y.; Qin, M.; Qu, X. Tuning Metallic $\mathrm{Co}_{0.85}$ Se Quantum Dots/Carbon Hollow Polyhedrons with Tertiary Hierarchical Structure for High-Performance Potassium Ion Batteries. Nano-Micro Lett. 2019, 11, 96.

(8) Liu, H.; Li, C.; Zhang, H. P.; Fu, L. J.; Wu, Y. P.; Wu, H. Q. Kinetic Study on $\mathrm{LiFePO}_{4} / \mathrm{C}$ Nanocomposites Synthesized by Solid State Technique. J. Power Sources 2006, 159, 717-720.

(9) Ge, X.; Liu, S.; Qiao, M.; Du, Y.; Li, Y.; Bao, J.; Zhou, X. Enabling Superior Electrochemical Properties for Highly Efficient Potassium Storage by Impregnating Ultrafine Sb Nanocrystals within Nanochannel-Containing Carbon Nanofibers. Angew. Chem., Int. Ed. 2019, 58, 14578-14583. 